\title{
And the Winner is... Awards for the Integration of Science and Practice in Psychology
}

\author{
James C. Overholser ${ }^{1} \cdot$ Eleanor E. Beale ${ }^{1}$ (i)
}

Published online: 23 August 2018

(c) Springer Science+Business Media, LLC, part of Springer Nature 2018

\begin{abstract}
Psychotherapists from all fields perform difficult and challenging work, trying to help their clients gain insight into their problems and make lasting changes in their thoughts and behaviors. Unfortunately, too often the work of a psychotherapist is minimized, neglected, or disregarded. Where departmental or conference awards may be presented regularly, public recognition for evidence-based and clinically-relevant published work is lacking. The present paper aims to acknowledge the most valuable recent accomplishments in the field of mental health assessment and treatment. Nominations were accepted for works published during 2017, papers of enduring value, and most valuable psychologist, and votes were cast by a panel of judges. These valuable contributions are recommended for all psychotherapists who hope to improve their work with clients.
\end{abstract}

Keywords Psychology $\cdot$ Award $\cdot$ Recognition $\cdot$ Psychotherapy

The Journal of Contemporary Psychotherapy has initiated an annual award celebration for professionals who devote their career to the empowerment of others. The present article will assign awards to various clinicians and scholars as a way of expressing appreciation for their work devoted to the refinement and improvement of psychotherapy. These awards will identify the top contributions published in scholarly outlets during the year 2017, published papers of enduring value, and most valuable psychologist.

In March of 2018, active members of the Journal of Contemporary Psychotherapy Editorial Board were asked by the authors (note: James C. Overholser is Editor of Journal of Contemporary Psychotherapy) to submit nominations for entries in any of the award categories, but they could not nominate their own work or the work of their colleagues, current students, or former students. They were encouraged to nominate papers that were published in any scholarly journal. Furthermore, in an effort to remain informed and unbiased, the JCP editorial staff reviewed 3920 journal articles published during 2017 in the following 30 journals: Acta Psychiatrica Scandinavica; American Journal of

Eleanor E. Beale

eeb72@case.edu

1 Department of Psychological Sciences, Case Western Reserve University, 1220 Bellflower Road, Cleveland, OH 44106-7123, USA
Orthopsychiatry; American Psychologist; JAMA Psychiatry; Assessment; Behavior Research and Therapy; Behavior Therapy; Clinical Psychology Review; Clinical Psychology: Science and Practice; Cognitive Therapy and Research; Comprehensive Psychiatry; International Journal of Cognitive Therapy; International Journal of Psychology and Counseling; International Journal of Psychiatry in Medicine; Journal of Abnormal Psychology; Journal of Affective Disorders; Journal of Behavior Therapy and Experimental Psychiatry; Journal of Clinical Psychiatry; Journal of Clinical Psychology; Journal of Clinical Child \& Adolescent Psychology; Journal of Consulting and Clinical Psychology; Journal of Contemporary Psychotherapy; Journal of Nervous and Mental Disease; Journal of Personality Assessment; Personality and Individual Differences; Personality Disorders: Theory, Research, and Treatment; Professional Psychology: Research and Practice; Psychological Assessment; Psychological Bulletin; and Psychotherapy. The particular subset of journals selected includes all long-established, well-respected, printed publications. These journals were chosen due to their high likelihood to publish high-quality work that relates to psychological treatments, while striving to connect research science to clinical practice.

For each category, we provide the top four submissions, along with a brief summary of the winning entry. These awards should be objective indicators of high-quality contributions to the field, unbiased by personal relationships that 
have developed with various colleagues and collaborators. Final winners were decided by a committee that reviewed all nominees and voted for the top contribution as well as their choice of alternate winner.

\section{Award for Most Valuable Contribution in a Review Article or Theoretical Paper}

This award represents the rigor required to publish a scholarly review paper. The published article integrates science and practice in a scholarly manner, and the article provides new insights into mental illness or its treatment. The authors have moved the field forward with new ideas instead of a simple review of previous findings. Nominees for most valuable contribution in a review article or theoretical paper are:

Brewer, C., Streel, E., \& Skinner, M. (2017). Supervised Disulfiram's superior effectiveness in alcoholism treatment: Ethical, methodological, and psychological aspects. Alcohol and Alcoholism, 52(2), 213-219.

Watkins, C. E. (2017a). Convergence in psychotherapy supervision: A common factors, common processes, common practices perspective. Journal of Psychotherapy Integration, 27(2), 140-152.

Meneses, R. W., \& Larkin, M. (2017). The experience of empathy: Intuitive, sympathetic, and intellectual aspects of social understanding. Journal of Humanistic Psychology, 57(1), 3-32.

Webster, G. D., Smith, C. V., Brunell, (A) B., Paddock, E. L., \& Nezlek, J. (B) (2017). Can Rosenberg's (1965) Stability of Self Scale capture within-person self-esteem variability? Meta-analytic validity and test-retest reliability. Journal of Research in Personality, 69, 156-169.

And the winner is... Watkins (2017a) and the review of supervision practices. Watkins has published a tremendous amount of work on clinical supervision, confronting issues about the supervisory relationship (Watkins 2015), the alliance needed for effective supervision (Watkins 2015), and the need for supervisor humility (Watkins et al. 2016). His work has provided a comprehensive framework for effective supervision (Watkins 2017; Watkins et al. 2015; Watkins and Scaturo 2013) promoting the development of the trainee's professional identity (Watkins 2016). Additional articles (e.g., Watkins 2011, 2012) provide valuable insights into the mind and strategies of the supervisor. In the present 2017 article, Watkins formulates 50 commonalities that create a cross-theoretical template for effective psychotherapy supervision. The thorough and interesting review contends that while psychotherapists may vary by model and theoretical orientation, the majority of these commonalities will be shared across all supervision experiences whether targeted toward psychotherapy, development, or social roles. This winning article focuses on an often-overlooked aspect of psychological training and highlights important features that lead to supervisory success. Dr. Watkins says (personal communication May 21, 2018), "Psychotherapy supervisors, I contend, are far, far more alike than different in the supervisory essentials in which they engage. But is there any sound basis for my contention? The Convergence paper reflects my effort to answer that question. By reviewing the supervision literature, trying to studiously look across the full spectrum of supervision perspectives and identify a common core of supervisory conceptualization and conduct, what emerged was a cross-cutting, trans-theoretical foundation: A common factors, common processes, common practices supervision perspective."

\section{Awards for Most Valuable Paper (MVP) on Assorted Clinical Topics}

These awards acknowledge the most important contributions made in journal articles that were published during 2017, examining issues related to the assessment, diagnosis, etiology, prognosis, treatment, or prevention of different forms of mental illness. The top papers focused on psychiatric patients instead of convenience samples and confronted strategies that could easily translate into actual clinical practice. Nominated papers show efforts to integrate the science and practice of psychology, as seen in either the collection of empirical data, or the reliance on empirical findings to guide innovative strategies that help to improve the understanding or treatment of a specific form of mental illness.

\section{Award for Most Valuable Paper on Depression or Suicide Risk}

Depression is an important topic for all mental health care providers. Furthermore, skilled understanding of suicide risk provides a unique area where a psychotherapist could potentially save a person's life. Thus, these topics are central to the field, and the scholars are all deserving of awards. The nominees for most valuable paper on depression or suicide risk are:

Franklin, J. C., Ribeiro, J. D., Fox, K. R., Bentley, K. H., Kleiman, E. M., Huang, X., Musacchio, K. M., Jaroszewski, A. C., Chang, B. P., \& Nock, M. K. (2017). Risk factors for suicidal thoughts and behaviors: A metaanalysis of 50 years of research. Psychological bulletin, 143(2), 187.

Chu, C., Van Orden, K. A., Ribeiro, J. D., \& Joiner, T. E. (2017). Does the timing of suicide risk assessments influ- 
ence ratings of risk severity? Professional Psychology: Research and Practice, 48(2), 107-114.

Kleinstäuber, M., Reuter, M., Doll, N., \& Fallgatter, A. J. (2017). Rock climbing and acute emotion regulation in patients with major depressive disorder in the context of a psychological inpatient treatment: a controlled pilot trial. Psychology Research and Behavior Management, 10, 277-281.

Cuijpers, P. (2017). Four decades of outcome research on psychotherapies for adult depression: An overview of a series of meta-analyses. Canadian Psychology, 58(1), 7-19.

And the winner is... Franklin and colleagues (2017) for their comprehensive review of suicide risk factors. In this thorough and impressive meta-analysis, Franklin et al. combine 50 years of suicide research to assess the current accuracy of known risk factors and to determine the progress that has been in made in researching this important topic. Using well-constructed meta-analytic techniques, the present paper determined that the predictive power of known risk factors of suicidal thoughts and behaviors is only slightly better than chance. The extensive review utilizes modern statistical techniques to suggest directions for future research and emphasizes the need for greater focus on algorithms and technology. The expansive nature of this meta-analysis, the impactful topic of risk factors for suicide, and the innovative suggestions for future research directions make this article stand out as monumental for the health care field. Dr. Franklin says (personal communication May 21, 2018), "In transitioning into the suicide research field, I was very confused by the large and often contradictory literature on suicide risk factors. To try and make sense of this literature, my colleagues and I decided to try to put together a metaanalysis of all of the relevant studies we could find. We were surprised and initially disappointed by the findings (i.e., hundreds of things predict suicidality slightly better than chance, but nothing predicts much better than this); however, we have since been inspired by these findings to take a new approach to understanding and accounting for suicide risk (e.g., complexity theory, machine learning)."

\section{Award for Most Valuable Paper on Anxiety or Trauma}

Publications on anxiety and trauma can cover a wide range of issues, problems, and situational triggers. In order to be relevant to the average psychotherapist, these papers are best when they are based on work with clinical samples, working to understand clients who have been diagnosed with an anxiety disorder or individuals who have encountered a traumatic life event. Nominees for the most valuable paper on anxiety or trauma are:

Pearl, S. B., \& Norton, P. J. (2017). Transdiagnostic versus diagnosis specific cognitive behavioural therapies for anxiety: A meta-analysis. Journal of Anxiety Disorders, 46, 11-24.

Resick, P. A., Wachen, J. S., Dondanville, K. A., Pruiksma, K. E., Yarvis, J. S., Peterson, A. L., Mintz, J., Borah, E. V., Brundige, A., \& Hembree, E. A. (2017). Effect of group vs individual cognitive processing therapy in active-duty military seeking treatment for posttraumatic stress disorder: A randomized clinical trial. JAMA Psychiatry, 74(1), 28-36.

Katz, D., Rector, N. A., \& Riskind, J. (2017). Reduction in looming cognitive style in cognitive-behavioral therapy: Effect on post-treatment symptoms across anxiety disorders and within Generalized Anxiety Disorder. International Journal of Cognitive Therapy, 10(4), 346-358. Rachamim, L., Shalom, J. G., Helpman, L., \& Mirochnik, I. (2017). Developmentally focused cognitive case conceptualization for toddlers and preschoolers with posttraumatic symptoms following a medical trauma. International Journal of Cognitive Therapy, 10(4), 330-345.

And the winner is... Resik and colleagues (2017) for their impressive study on the treatment of Post-Traumatic Stress Disorder (PTSD) among the military. Resik et al. conducted a randomized controlled trial in an active-duty military population, looking at the effectiveness of cognitive processing therapy (CPT) on PTSD, depression, and suicidality symptoms. By focusing on individuals in active-duty, this study applied an evidence-based treatment in a new and important setting. Additionally, by testing CPT in both individual and group formats, Resik et al. investigated an important question regarding the most efficient modality for treatment in such a high-risk population. The resulting effectiveness of CPT, particularly in an individual setting, suggests a promising method of early intervention in a very important clinical population. Dr. Resick says (personal communication May 21, 2018), "This study was conducted within the STRONG STAR Consortium led by Dr. Alan Peterson. There were many people involved in the successful completion of this project at both Fort Hood Texas and the University of Texas Health Science Center San Antonio. Conducting a randomized controlled trial on a military base with active service members also required a great deal of coordination with the command of the base and the cooperation of many service members. It would not have been possible to compare individual and group cognitive processing therapy in many other environments because of the need to randomize so many people at once. This was a unique opportunity to study this important question in the treatment of PTSD." 


\section{Award for Most Valuable Paper on Schizophrenia or Psychosis}

All forms of psychotic disorders present unique challenges to patients, their families, and the clinicians who are trying to help them. Psychological treatments can be especially complicated when the client is struggling with hallucinations, delusions, or some form of thought disorder. Clinical work and research on psychotic disorders is essential for improving the care and treatment of these vulnerable individuals. Nominees for the most valuable paper on schizophrenia or psychosis are:

Cella, M., Preti, A., Edwards, C., Dow, T., \& Wykes, T. (2017). Cognitive remediation for negative symptoms of schizophrenia: a network meta-analysis. Clinical Psychology Review, 52, 43-51.

Hjorthøj, C., Stürup, A. E., McGrath, J. J., \& Nordentoft, M. (2017). Years of potential life lost and life expectancy in schizophrenia: A systematic review and meta-analysis. Lancet Psychiatry, 4(4), 295-301.

Sin, J., \& Spain, D. (2017). Psychological interventions for trauma in individuals who have psychosis: a systematic review and meta-analysis. Psychosis, 9(1), 67-81. Fusar-Poli, P., Rutigliano, G., Stahl, D., Davies, C., Bonoldi, I., Reilly, T., \& McGuire, P. (2017). Development and validation of a clinically based risk calculator for the transdiagnostic prediction of psychosis. JAMA Psychiatry, 74(5), 493-500.

And the winner is... Cella and colleagues (2017) for their important work on cognitive remediation in schizophrenia. Cella et al. investigated the efficacy of cognitive remediation treatment on reducing the negative symptoms of schizophrenia. Through meta-analytic techniques, cognitive remediation was shown to have a lasting effect in the reduction of negative symptoms. The present study conducted by Cella et al. stands out by its assessment of not only a population with serious mental illness, but also a particular subset of that population that is often resistant to other common methods of intervention, such as medication. Applying cognitive remediation in this novel manner could prove an important option for successful treatment of schizophrenia. Dr. Cella says (personal communication May 22, 2018), "Intervention for negative symptoms in people with psychosis is a neglected area. This is despite the large contribution this symptom cluster has to longterm disability. Our clinical work on cognitive remediation showed that this intervention can be beneficial to reduce the burden of negative symptoms and improve functioning in people with psychosis. This is why we embarked in this meta-analysis work: to evaluate more systematically the potential of this intervention. Diligent literature search, data extraction, trial quality evaluation and analysis took us many hours of hard work. But we believe our paper has provided solid evidence in support of the usefulness of cognitive remediation for reducing the burden of negative symptoms in people in psychosis. We hope this work will provide solid footing for further implementation of this therapy in psychosis care and lead the way to research exploring the active ingredients of cognitive remediation responsible for negative symptoms reduction. This may help to develop novel psychological interventions targeting negative symptom which are currently much needed."

\section{Award for Most Valuable Paper on Personality Disorders}

Personality disorders are pervasive throughout society, in clinical and nonclinical settings. However, many mental health professionals lack a firm understanding of the different forms of personality disorder. Publications on assessment can be useful, helping clinicians to improve their ability to identify and properly diagnose these persistent problems. Furthermore, psychotherapy for personality disorders usually requires long-term therapy with a comprehensive plan that guides the treatment. Nominees for the most valuable paper on personality disorders are:

Waugh, M. H., Hopwood, C. J., Krueger, R. F., Morey, L. C., Pincus, A. L., \& Wright, A. G. (2017). Psychological assessment with the DSM-5 Alternative Model for Personality Disorders: Tradition and innovation. Professional Psychology: Research and Practice, 48(2), 79-89. Wilson, S., Stroud, C. B., \& Durbin, C. E. (2017). Interpersonal dysfunction in personality disorders: A metaanalytic review. Psychological Bulletin, 143(7), 677-734. Timoney, L. R., Walsh, Z., Shea, M. T., Yen, S., Ansell, E. B., Grilo, C. M., McGlashan, T. H., Stout, R. L., Bender, D. S., \& Skodol, A. E. (2017). Personality and life events in a personality disorder sample. Personality Disorders: Theory, Research, and Treatment, 8(4), 376.

South, S. C., \& Jarnecke, A. M. (2017). Structural equation modeling of personality disorders and pathological personality traits. Personality Disorders: Theory, Research, and Treatment, 8(2), 113-129.

And the winner is... Wilson, Stroud and Durbin (2017) for their review of interpersonal problems among patients with personality disorders. With the publication of the DSM-V in 2012, there ensued a great deal of controversy regarding the proposed alternative dimensional model of personality disorders. In the winning article, Wilson et al. continue an important investigation of the validity of the 
current model of personality disorders, as well as the impact of disturbance in self and functioning as suggested by the newer dimensional model. Conducting the first systematic assessment of the associations between personality disorders and interpersonal functioning, Wilson et al. take an important step in better understanding the nuanced relationships among these constructs. Dr. Wilson says (personal communication June 4, 2018), "This meta-analysis was quite a timeconsuming project (6 years of work) but the final results are very rewarding. We synthesized over a hundred studies with thousands of participants that collectively reflect researchers' and clinicians' great interest in better understanding personality disorders and their implications. We hope the knowledge gained from this work helps researchers, clinicians, and the individuals affected by personality disorders by informing the most accurate assessment, diagnosis, and effective treatments."

\section{Award for Most Valuable Paper on Assessment or Diagnosis}

This award acknowledges the most important contribution made in a journal article that was published during 2017, examining issues related to the psychological assessment or the diagnosis of mental illness. Nominated papers focused on psychiatric patients instead of convenience samples, and confronted strategies that could easily translate into actual clinical practice. These papers show efforts to integrate the science and practice of psychology, as seen in either the collection of empirical data, or the reliance on empirical findings to guide innovative strategies that help to improve the evaluation and understanding of psychological problems. These papers confronted psychological evaluations in terms of interviews, questionnaires, or performance-based measures. The findings have clear relevance to clinical practice, and the strategies are likely to be beneficial to the average practicing clinician. Nominees for the most valuable paper on assessment or diagnosis are:

Provenzi, L., Menichetti, J., Coin, R., \& Aschieri, F. (2017). Psychological assessment as an intervention with couples: Single case application of collaborative techniques in clinical practice. Professional Psychology: Research and Practice, 48(2), 90-97.

Greiff, S., \& Heene, M. (2017). Why psychological assessment needs to start worrying about model fit. European Journal of Psychological Assessment, 33 (5), 313-317.

Filipiak, M., Tarnowska, M., Zalewski, B., \& Paluchowski, W. J. (2017). On the system of continuing education in psychological assessment in Poland: A dis- cussion summary. Roczniki Psychologiczne / Annals of Psychology, 18(2), 251-260.

Ormachea, P. A., Lovins, B. K., Eagleman, D. M., Davenport, S., Jarman, A., \& Haarsma, G. (2017). The Role of Tablet-Based Psychological Tasks in Risk Assessment. Criminal Justice and Behavior, 44(8), 993-1008.

And the winner is... Provenzi, Menichetti, Coin, \& Aschieri (2017). Provenzi et al. take an important look at the utility of including the therapy client in the process of assessment. Using assessment as a therapeutic intervention in and of itself has been done before, but it is rarely treated as standard practice. Through their case example, Provenzi et al. illuminate the benefit of intervention and summary sessions driven by collaboration of therapist and client through assessment feedback. Using the structured and validated tools provided by assessment techniques to educate clients presents an alternative and useful therapeutic technique. Dr. Provenzi says (personal communication May 22, 2018), "We report a single-case application of collaborative assessment techniques to clinical psychological consultation with a marital couple. The use of assessment techniques as a means to enhance clients' empathy and compassion and to promote positive psychological change has been advanced and well structured by Conny Fischer (2000) and Steve Finn (2007). In this contribution we further suggest that the results of psychological assessment (i.e., MMPI-2, Rorschach) can be fruitfully shared with couples to help them reframe the narratives of their story and functioning as well as to promote empathy toward their actual life challenges. Nevertheless, I would like to highlight that a specific education is needed to guide the use of collaborative assessment techniques in clinical practice. To this extent, I am deeply thankful to Steve Finn, as he is both a wise professor and a special human being: not only the contents of his lessons, but also the way he is able to be close and dedicated to clients and trainees is one of the most important lessons I take with me in my daily clinical practice as a psychotherapist."

\section{Award for Most Valuable Paper on Psychological Treatment}

This award acknowledges the most important contribution made in a journal article that was published during 2017, examining issues related to the treatment for any form of mental illness. Nominated papers focused on psychiatric patients instead of convenience samples and confronted strategies that could easily translate into actual clinical practice. These papers show efforts to integrate the science and practice of psychology, as seen in either the collection of empirical data or the reliance on empirical findings to guide innovative strategies that help to improve 
the psychological treatment of any type of mental illness. These papers confronted issues related to psychotherapy process or outcome from a theoretical or empirical stance. The average clinician is likely to value the new insights that derive from this paper. Nominees for the most valuable paper on psychological treatment are:

Stephenson, L., \& Hale, B. (2017). An exploration into effectiveness of Existential-Phenomenological Therapy as a UK NHS psychological treatment intervention. Journal of Humanistic Psychology, 0022167817719178.

Goodcase, E. T., \& Love, H. A. (2017). From despair to integrity: Using narrative therapy for older individuals in Erikson's last stage of identity development. Clinical Social Work Journal, 45(4), 354-363.

Hill, C. E., Spiegel, S. B., Hoffman, M. A., Kivlighan Jr, D. M., \& Gelso, C. J. (2017). Therapist expertise in psychotherapy revisited. The Counseling Psychologist, 45(1), 7-53.

Miller, W. R., \& Moyers, T. B. (2017). Motivational interviewing and the clinical science of Carl Rogers. Journal of Consulting and Clinical Psychology, 85(8), 757-766.

And the winner is... Miller and Moyer (2017) for their informative article about Motivational Interviewing. In the present article, Miller and Moyer outline the strength of the bridge that Motivational Interviewing creates between evidence-based practice and the therapeutic relationship. Motivational Interviewing has developed a vast following of clinicians and researchers who see the value of building upon the seminal work of Carl Rogers. The wide reaching application of Motivational Interviewing not only in psychological treatment, but also health treatment is why understanding the origins and principles of this intervention is so important. The basis of Motivational Interviewing in the work and practice of Carl Rogers emphasizes the creation of a therapeutic alliance between therapist and client in the process of seeking meaningful change. Motivational Interviewing deserves further investigation to determine what particular aspects are most effective and vital to its utility. Dr. Miller says (personal communication May 20, 2018), "We are simply continuing the clinical science tradition pioneered by Carl Rogers to study how psychotherapy processes influence client change. We started from observing and reflecting on clinical practice as Rogers did, generating and testing hypotheses about therapeutic relationship. Motivational interviewing is now the most active area of research on a person-centered approach, with a thousand controlled trials currently described in the scientific literature."

\section{Award for Most Valuable Paper with Enduring Impact}

This award highlights the best journal article with lasting merit. Some important articles have withstood the test of time, and continue to share wisdom and insights with the average reader. The original articles were all published more than 30 years earlier, but they all still retain value and important ideas. Each of these articles should be required reading by all graduate students in clinical psychology and counseling psychology. Nominees for the best paper with enduring value include:

Jones, M. C. (1924a). A laboratory study of fear: The case of Peter. Pedogogical Seminary and Journal of Genetic Psychology, 31, 308-315.

Jones, M. C. (1924b). The elimination of children's fears. Journal of Experimental Psychology, 7, 382-390. Ellis, A. (1982). Must most psychotherapists remain as incompetent as they now are? Journal of Contemporary Psychotherapy, 13 (1), 17-28.

Boardman, W. K. (1962). Rusty: A brief behavior disorder. Journal of Consulting Psychology, 26(4), 293-297. Kendall, P. C., Howard, B. L., \& Epps, J. (1988). The anxious child: Cognitive-behavioral treatment strategies. Behavior Modification, 12(2), 281-310.

And the winner is... Kendall, Howard, and Epps (1988) whose thoughtful report on the treatment of childhood anxiety qualifies for the award in the first year of eligibility. At the time of publication, thorough understanding of the cognitive-behavioral aspects involved in the treatment of anxiety were not well understood. Thirty years later psychologists still have a good deal to learn to improve success rates of anxiety treatment despite the greats strides that have been made. In the winning article, Kendall and colleagues address many of the central tenants of cognitive-behavioral therapy that remain important today. Dr. Kendall has devoted his career to the treatment of problems among children and teenagers, going back 45 years (Finch et al. 1974). He developed the Coping Cat Program for the treatment of anxiety in youth (Podell et al. 2010), publishing a therapist manual (Kendall and Hedtke 2006) as well as data to support its effectiveness (Kendall 1994). His incredible number of publications have set the standard for evidence-based practice. As an active clinician, he has lived by the ideals of the Boulder model, using his clinical experiences to refine his applied research. He has argued for maintaining flexibility within the use of evidence-based treatment programs (Beidas et al. 2010; Kendall et al. 1998). In addressing these issues with regards to children, Kendall et al. (1998) provide valuable 
insight into the very distressing and practical issues that come about in treating an anxious child. Additionally, the observations made in the seminal paper include multiple aspects of mental illness, such as physiology, environmental impact, and clinically significant change. The thorough overview of anxiety in children as presented by Kendall et al. (1998) continues to have utility in the education of future psychologists and the application of therapeutic techniques. Although we are granting an award for one published article, we fully expect to see Dr. Kendall's name again for the lifetime achievement award. Dr. Kendall says (personal communication May 24, 2018), "As is often mentioned as part of a review of the topic, anxiety in childhood is considered a gateway disorder for mental health problems larger in life - adult anxiety, depression, and substance use being examples. Fortunately, recent evidence suggests that successful treatment of childhood anxiety reduces risk of these unwanted sequelae. I have spent over 35 years designing, revising, and evaluating optimal strategies for anxious youth and I am so very thankful to learn that people care about treating anxiety in children. I started working with impulsive youth just about the time that ADD and then ADHD became a central theme within children's mental health. Medications were being found to be helpful and psychological treatments were less so. I shifted from ADHD/impulsivity to anxiety at the same time that I shifted from the University of Minnesota to Temple University. Although there have been speed bumps in the path and we have modified the route, several core ingredients for treating anxiety in youth have withstood the test of time (and empirical evaluation). Exposure to situations that produce distressing anxiety, along with cognitive preparation (skill building) and post-exposure processing of the exposure experience (Did the catastrophe happen?) continue to be supported as meaningful strategies for helping anxious youth manage their distressing anxiety."

\section{Award for Most Valuable Psychotherapist}

The award for most valuable psychotherapist highlights the career of a living psychotherapist who has lived by the ideals of the scientist-practitioner model. The winner of this lifetime achievement award is a professional who has spent his or her career making valuable contributions to the areas or mental health and psychological treatments. The person's contributions may extend across many years of professional work, and the person's contributions have helped to shape the current views on a disorder or its treatment. Nominees include the following leaders of the field:
Aaron T. Beck whose massive contributions over his lengthy career have reshaped our approach to psychotherapy, especially for clients who are struggling with depression or anxiety.

Pim Cuijpers who has published extensively on a wide range of topics, and whose career exemplifies a focus on evidence-based practice.

David Barlow whose career has demonstrated the ideals of the Boulder model, publishing numerous books and journal articles that delve into the depths of psychological treatments.

Don Meichenbaum whose work helped to pioneer the various approaches to self-instructional training, stress inoculation therapy, and narrative approaches to treatment.

And the winner is... Aaron T. Beck. Clearly, Dr. Beck is one of the most influential psychotherapists of all time. Over his long and productive career, he has published more than 25 books and more than 600 journal articles. His works have set the highest standard for integrating the science and practice in the field of mental health care. He was an early pioneer in the development of cognitive therapy, as well as a developer of a myriad of clinical assessment tools that have been adopted world-wide. His early publications (Beck 1952; Beck and Valin 1953) confronted important issues relevant to specific clients. Then, he published important research on new assessment measures designed to assess depression (Beck et al. 1961), hopelessness (Beck et al. 1974b, 1989), suicidal thoughts (Beck et al. 1979a, 1988), and suicidal intent (Beck et al. 1974a). His influential book on the treatment of depression (Beck et al. 1979b) has been cited by almost 20,000 publications, and the ideas outlined reshaped the approach to evidence-based practice. His vast contributions to the field of mental health care have had a profound influence on most clinicians and countless numbers of patients. Dr. Beck says (personal communication May 21, 2018), "I have always found in my work with patients as well as my teaching that a strong empirically validated, theoretical framework embedded in the formulation of the case is one essential of good psychotherapy. The next important ingredient is a solid therapeutic relationship with the individual-something that is crucial and has a strong therapeutic impact in itself for the severely mentally ill. Finally, I recommend a flexible and humanistic therapeutic approach, which is based on the case formulation and is directed towards activating the positive aspects of the personality."

\section{Conclusion}

During "award season", the entertainment industry hosts a different televised award ceremony each week. During these glamorous events, celebrities praise other celebrities 
for their major accomplishments. Often, these awards are presented not to the creative workers who write the songs or scripts, but to the actors who memorize words that have been written by others. Too often, these awards highlight the beautiful people who have fame and fortune, while providing mindless entertainment to the masses. Meanwhile, psychotherapists and researchers devote their lives to scholarship and helping others, often under conditions of minor anonymity.

The present article highlights important contributions that have been made to the field of psychotherapy. If we aim to remain true to the title of the journal, it is useful to focus on creative and helpful ideas that are published recently in order to highlight the best of contemporary psychotherapy. This acknowledgement of work published in the year 2017 serves as an attempt to seek out, recognize, and honor vital progress in evidence-based and clinically relevant psychological work. Every effort to further what we as researchers and clinicians know about assessment, therapy, intervention, and practice is important. We thank each and every of the above contributors, as well as those who did not end up on the final nominations list. Congratulations to our winners, and keep up the good work.

\section{Editorial Postscript}

Finally, as editor of the Journal of Contemporary Psychotherapy, I want to thank the editorial board and the ad hoc reviewers. During the past year, the following colleagues have shared their expertise as ad hoc reviewers: Haifa Mohammed Saleh Al Gahtani, Page Anderson, Emily Ansell, Erin Lungren Babbitt, Allison Baier, Catherine Barber, Luz Bascunan, Melissa Armstrong Brine, Kimberly Burkhart, Eduard Canatal, Kerry Cannity, Megan Carl, Jean Carter, Adam Clark, Antonia Csillik, Louanne Davis, John Donohue, Peter Ebigbo, Christopher Eckhardt, George Eifert, Tom Ellis, Erica Gergeley, Gulsen Erden, Stuart Fisher, Lorainne Freedle, Haruo Fujino, Volkan Gulum, Huw Green, Jay Hamm, Marco-Antonio Hartmann, Jeffrey Hine, Carolyn Ievers-Landis, Vanessa Jensen, Cary Jordan, Ioanna Kousteni, Elisa Krakow, Ingrid Krecko, Valery Krupnik, Jeffrey Kuentzel, Itzhak Alvin Lander, Bethany Leonardt, Whitney Loring, Duane Lundervold, Jason Luoma, Dan Marques, Sarah Elizabeth Meinikoff, Matthew Merced, Brian Miller, Dawn Moeller, Katherine Myers, John O'Connor, William O'Donohue, Giovanni Ottoboni, Tracy Prout, Diego Romaioli, Beth Mishkind Roth, Christina Sheerin, Alycia Roberts, Lauren Rogers-Sirin, Sarah Spannagel, Maryanne Reilly Spong, Ladislav Timulak, Tamiko Lemberger-Truelove, and Richard Vuijk.

\section{Compliance with Ethical Standards}

Conflict of interest The authors declare that they have no conflict of interest.

Ethical Approval This article does not contain any studies with human participants or animals performed by any of the authors.

\section{References}

Beck, A. T. (1952). Successful outpatient psychotherapy of a chronic schizophrenic with a delusion based on borrowed guilt. Psychiatry, 15(3), 305-312.

Beck, A. T., Brown, G., \& Steer, R. (1989). Prediction of eventual suicide in psychiatric inpatients by clinical ratings of hopelessness. Journal of Consulting and Clinical Psychology, 57(2), 309.

Beck, A. T., Kovacs, M., \& Weissman, A. (1979a). Assessment of suicidal intention: The scale for suicide ideation. Journal of Consulting and Clinical Psychology, 47(2), 343-352.

Beck, A. T., Rush, A. J., Shaw, B., \& Emery, G. (1979b). Cognitive therapy of depression. New York: Guilford Press.

Beck, A. T., Schuyler, D., \& Herman, I. (1974a). Development of suicidal intent scales. In A. T. Beck, H. Resnick, \& D. Lettieri (Eds.), The prediction of suicide (pp. 45-56). Bowie, MD: Charles Press.

Beck, A. T., Steer, R., \& Ranieri, W. (1988). Scale for suicide ideation: Psychometric properties of a self-report version. Journal of Clinical Psychology, 44(4), 499-505.

Beck, A. T., \& Valin, S. (1953). Psychotic depressive reactions in soldiers who accidentally killed their buddies. American Journal of Psychiatry, 110(5), 347-353.

Beck, A. T., Ward, C., Mendelson, M., Mock, J., \& Erbaugh, J. (1961). An inventory for measuring. Archives of General Psychiatry, 4, 561-571.

Beck, A. T., Weissman, A., Lester, D., \& Trexler, L. (1974b). The measurement of pessimism: The Hopelessness Scale. Journal of Consulting and Clinical Psychology, 42(6), 861-865.

Beidas, R., Benjamin, C., Puleo, C., Edmunds, J., \& Kendall, P. C. (2010). Flexible applications of the coping cat program for anxious youth. Cognitive and Behavioral Practice, 17(2), 142-153.

Finch, A. J., Kendall, P. C., \& Montgomery, L. E. (1974). Multidimensionality of anxiety in children. Journal of Abnormal Child Psychology, 2(4), 331-336.

Finn, S. (2007). In our clients' shoes: Theory and techniques of therapeutic assessment. Mahwah: Erlbaum.

Fischer, C. (2000). Collaborative, individualized assessment. Journal of Personality Assessment, 74, 2-14.

Kendall, P. C. (1994). Treating anxiety disorders in children: Results of a randomized clinical trial. Journal of Consulting and Clinical Psychology, 62(1), 100-110.

Kendall, P. C., Chu, B., Gifford, A., Hayes, C., \& Nauta, M. (1998). Breathing life into a manual: Flexibility and creativity with manual-based treatments. Cognitive and Behavioral Practice, 5(2), 177-198.

Kendall, P. C., \& Hedtke, K. (2006). Cognitive-behavioral therapy for anxious children: Therapist manual. Ardmore: Workbook Publishing.

Podell, J., Mychailyszyn, M., Edmunds, J., Puleo, C., \& Kendall, P. C. (2010). The Coping Cat Program for anxious youth: The FEAR plan comes to life. Cognitive and Behavioral Practice, 17(2), $132-141$.

Watkins, C. E. (2011). Does psychotherapy supervision contribute to patient outcomes? Considering thirty years of research. The Clinical Supervisor, 30(2), 235-256. 
Watkins, C. E. (2011). The real relationship in psychotherapy supervision. American Journal of Psychotherapy, 65(2), 99-116.

Watkins, C. E. (2012). Psychotherapy supervision in the new millennium: Competency-based, evidence-based, particularized, and energized. Journal of Contemporary Psychotherapy, 42(3), 193-203.

Watkins, C. E. (2015). The learning alliance in psychoanalytic supervision: A fifty-year retrospective and prospective. Psychoanalytic Psychology, 32(3), 451-481.

Watkins, C. E. (2015). The real relationship in psychotherapy supervision: A trans-theoretical common factor. International Journal of Psychotherapy, 19(3), 20-26.

Watkins, C. E. (2016). Listening, learning, and development in psychoanalytic supervision: A self psychology perspective. Psychoanalytic Psychology, 33(3), 437-471.

Watkins, C. E. (2017). How does psychotherapy supervision work? Contributions of connection, conception, allegiance, and action. Journal of Psychotherapy Integration, 27(2), 201-217.
Watkins, C. E. (2017). Reconsidering parallel process in psychotherapy supervision: On parsimony, rival hypotheses, and alternate explanations. Psychoanalytic Psychology, 34(4), 506-515.

Watkins, C. E., Budge, S., \& Callahan, J. (2015). Common and specific factors converging in psychotherapy supervision. Journal of Psychotherapy Integration, 25(3), 214-235.

Watkins, C. E., Hook, J., Ramaeker, J., \& Ramos, M. (2016). Repairing the ruptured supervisory alliance: Humility as a foundational virtue in clinical supervision. The Clinical Supervisor, 35(1), 22-41.

Watkins, C. E., \& Scaturo, D. J. (2013). Toward an integrative, learning-based model of psychotherapy supervision: Supervisory alliance, educational interventions, and supervisee learning/relearning. Journal of Psychotherapy Integration, 23(1), 75-95. 